\title{
Metabolic Stress Modulates Motor Patterning via AMP-Activated Protein Kinase
}

\author{
Corinne I. Rodgers-Garlick, Gary A. B. Armstrong, and R. Meldrum Robertson \\ Department of Biology, Queen's University, Kingston, Ontario K7L 3N6, Canada
}

Neural circuits are especially vulnerable to metabolic stress. The locust (Locusta migratoria) responds to anoxia by entering a coma during which neural and muscular systems shut down. During anoxic coma, arrest of the ventilatory central pattern generator is tightly correlated with an abrupt spreading depression (SD)-like increase in extracellular potassium concentration within the metathoracic neuropile. We examined the role of the AMP-activated protein kinase (AMPK), an evolutionarily conserved sensor of cellular energy status, in anoxia-induced ventilatory arrest and SD-like events in the locust. Perfusion of sodium azide $\left(\mathrm{NaN}_{3}\right.$; mitochondrial toxin) induced SD, temporary coma, and profound changes in the ventilatory motor pattern characterized as a rapid rhythm before coma and a slower rhythm following recovery. AMPK activation using 5-aminoimidazole-4-carboxamide ribonucleoside (AICAR) mimicked the motor pattern changes induced by $\mathrm{NaN}_{3}$ but did not induce $\mathrm{SD}$ and coma. The effects of $\mathrm{NaN}_{3}$ on the ventilatory rhythm were reversed by perfusion of compound-C (AMPK inhibitor) or glucose, and the effects of AICAR were also reversed by compound-C, confirming the modulatory roles of AMPK and energy status. Ouabain-induced recurring SD was suppressed by inhibition of AMPK and exacerbated by its activation. We show that the motor pattern changes induced by metabolic stress are not the result of SD alone, but that AMPK is necessary and sufficient for these changes and that AMPK activity strongly influences susceptibility to SD.

\section{Introduction}

Variation in oxygen levels can impair vital neuronal circuits and have drastic consequences for an organism's survival. At the cellular level, lack of adequate $\mathrm{O}_{2}$ results in disruption of protein synthesis, depletion of intracellular energy stores, opening of voltage-gated $\mathrm{Ca}^{2+}$ channels, and loss of ionic gradients leading to excitotoxicity and oxidative damage (Snider et al., 1999; Love, 2003). Regulatory mechanisms such as the AMP-activated protein kinase (AMPK) cascade are highly evolutionarily conserved (Pan and Hardie, 2002) and exist to monitor energy and mitigate the damaging effects of metabolic stress (Hardie et al., 2003; McCullough et al., 2005; $\mathrm{Li}$ and McCullough, 2010). Neurons are particularly vulnerable to metabolic stress, and there is considerable interest in the role of AMPK in neural health and dysfunction (Spasić et al., 2009); however, little is known of how energetic stress or AMPK modulate neural circuit function. We examined the effects of energetic stress on a locust model of CNS function, the ventilatory central pattern generator ( $\mathrm{vCPG}$ ), by characterizing the stress-induced changes in the activity of the $\mathrm{vCPG}$ in response to chemical anoxia using sodium azide $\left(\mathrm{NaN}_{3}\right)$ and testing the role of AMPK in mediating these effects.

Received Oct. 4, 2010; revised Dec. 13, 2010; accepted Jan. 7, 2011.

This research was funded by the Natural Sciences and Engineering Research Council of Canada to R.M.R. We thank David Andrew, Eve Marder, Les Buck, and Michael O'Donnell for their comments on a previous version of the manuscript and Jon Harrison for suggestions for measuring tracheal volume. We also thank Yeyao Yu for his help in collecting some of the data.

Correspondence should be addressed to Corinne I. Rodgers-Garlick, Department of Cell and Systems Biology, University of Toronto, Toronto, Ontario M5S 365, Canada. E-mail: corinne.rodgers@utoronto.ca.

DOI:10.1523/JNEUROSCI.5215-10.2011

Copyright $\odot 2011$ the authors $\quad 0270-6474 / 11 / 313207-10 \$ 15.00 / 0$
Locusts are tolerant of oxygen deprivation and can withstand hours of submersion under water (Armstrong et al., 2009) by entering a reversible stress-induced coma. Upon removal from anoxic conditions, nervous and muscular systems completely recover and locusts behave normally. Stress-induced coma, including arrest of vCPG operation, is associated with spreading depression (SD)-like events that share properties of SD in mammalian cerebral cortical tissue (Rodgers et al., 2007, 2009; Armstrong et al., 2009). These are characterized by abrupt $50-80 \mathrm{~mm}$ increases in extracellular potassium concentration $\left(\left[\mathrm{K}^{+}\right]_{\mathrm{o}}\right)$ within the ventilatory neuropile that coincide with vCPG shutdown. Our hypothesis is that stress-induced comas and associated SD-like events in the locust represent a protective strategy to cope with environmental stress by preventing neuronal hyperexcitation and energy collapse (Rodgers et al., 2010). Conceivably, energy levels would be maintained by entering a state of coma during which energyusing mechanisms that restore ion gradients are suspended (Rodgers et al., 2007; Staples and Buck, 2009). Notably, metabolic stresses can trigger the activation of signaling pathways before changes in ATP can be detected (Evans, 2006; Hardie et al., 2006).

AMPK is an evolutionarily conserved homeostatic regulator that senses cellular energy status (Hardie et al., 2003). Its activation in response to stress may initiate a switch in energy usage that improves energy status, thereby affecting energy-intensive neuronal systems. Given that ventilation is both an energy-requiring process and involved in providing oxygen to tissues, it is conceivable that $\mathrm{VCPG}$ output would be altered by AMPK activation during stress. We examined the effects of AMPK activation and inhibition on the ventilatory motor pattern to establish a role for AMPK in neural circuit modulation and to determine its modulatory effects on SD-like events induced by ouabain. Our results 
support the hypothesis that stress-induced comas and associated SD-like events in the locust comprise an adaptive response to conserve energy by decreasing metabolic demand and thus preventing metabolic compromise. We further suggest that these findings are relevant for understanding the pathology of periinfarct depolarizations associated with stroke by demonstrating that temporary loss of ion homeostasis is separable from longerterm effects mediated by the AMPK pathway.

\section{Materials and Methods}

Animals. All experiments were performed on adult male locusts, Locusta migratoria migratorioides (Reiche and Fairmaire, 1849), aged 3-5 weeks past imaginal ecdysis. Locusts were obtained from a crowded colony located in the Animal Care Facility of the Biosciences Complex at Queen's University (Kingston, Ontario, Canada). The colony was reared under a 12/12 h light/dark photoperiod at a room temperature of $30 \pm$ $1{ }^{\circ} \mathrm{C}$ during light hours and $26 \pm 1{ }^{\circ} \mathrm{C}$ during dark hours. Humidity was maintained at $23 \pm 1 \%$. Animals were provided with carrots, wheat seedlings, and an ad libitum mixture of 1 part skim milk powder, 1 part torula yeast, and 13 parts bran by volume.

Starvation, water immersion, and measurement of tracheal volume. Adult male locusts reared under the same conditions as those used for all other experiments were withheld food for 2, 4, and $6 \mathrm{~d}$ to test the interaction between starvation and the ability to tolerate suffocation by immersion under water. Animals were removed from the colony and injected with $10 \mu \mathrm{l}$ of either $10^{-1}$ M 5-aminoimidazole-4-carboxamide ribonucleoside (AICAR), an AMPK activator, or $10^{-3}$ M 6-[4-(2-piperidin-1-ylethoxy)-phenyl-]-3pyridin-4-ylpyrazolo-[1,5-a]-pyrimidine (compound-C), an AMPK inhibitor, into the hemocoel (Armstrong et al., 2009). Control locusts were injected with standard locust saline containing 0.5\% DMSO. Locusts were immersed in water $1 \mathrm{~h}$ after injection. Intact locusts that were fed and those that were starved for 2, 4, and $6 \mathrm{~d}$ were placed within a mesh-lidded clear plastic container that was then submerged in a larger bucket filled with room temperature water for $30 \mathrm{~min}$. Animals were trapped under water, and all were incapacitated by this treatment. Induction of anoxia in locusts by water immersion resulted in elevated escape movements followed by immobility and a subsequent short bout of seizure-like convulsions involving twitching, stretching, and trembling of the legs. Time to succumb was measured as the length of time between immersion under water and the observed seizure-like convulsions of the whole animal. After removal from the water, locusts were placed on their side on a piece of paper towel, and the time to recover ventilation was measured (Armstrong et al., 2009). The effects of starvation and of AICAR and compound-C on vulnerability to submersion under water were most clearly seen in locusts starved for $4 \mathrm{~d}$ and thus these results are presented; however, the results for 2 and $6 \mathrm{~d}$ of starvation were qualitatively similar.

We estimated tracheal volume using a water displacement method (Bartholomew and Barnhart, 1984). Individual locusts were submerged in water, and the time to succumb to anoxic coma was measured. The locust was blotted dry and weighed (submersion and blotting dry added $0.08 \pm 0.01 \mathrm{~g}$ to the weight) before being placed in a $50 \mathrm{ml}$ plastic syringe filled with water containing some dishwashing detergent ( $1 \mathrm{ml}$ of detergent per $250 \mathrm{ml}$ of tap water) and fitted with a valve. The air was expelled from the syringe, the syringe end was sealed, and a vacuum was applied by pulling on the plunger to draw the air out of the tracheae. Tracheal air was expelled from the syringe, and the process was repeated three times. The locust was removed from the syringe, blotted dry, and reweighed. The weight gained by this process was used as an estimate of tracheal volume, assuming the density of water to be $1 \mathrm{~g} / \mathrm{ml}$.

Semi-intact preparation. The appendages and pronotum were removed, and a dorsal midline incision was made. A corkboard was used to pin open the locust dorsal side up, allowing the gut, fat body, and air sacs to be removed and exposing the ventral nerve cord, metathoracic ganglion (MTG), and ventilatory nerves. The preparation was set up to prevent leakage and thus maximize the use of very small quantities of drugs by replacement of the bathing solution rather than by continuous superfusion. A metal plate was placed beneath the MTG to stabilize it, and nerves $2-5$ on both sides of the ganglion were severed at their roots to allow saline and drug entry into the neuropil. The MTG was bathed in standard locust saline containing the following (in mM): $147 \mathrm{NaCl}, 10$ $\mathrm{KCl}, 4 \mathrm{CaCl}_{2}, 3 \mathrm{NaOH}$, and $10 \mathrm{HEPES}$ buffer, $\mathrm{pH} 7.2$, which was applied manually by pipetting into the preparation above the MTG where the $\mathrm{vCPG}$ is located. A silver wire was inserted in the anterior portion of the thorax to ground the preparation.

Motor patterns. A suction electrode (World Precision Instruments) was used to obtain extracellular neurographic recordings of the ventilatory motor pattern. The suction electrode pipette was pulled to form a high resistance tip and then broken to the appropriate size, fire-polished, and applied to the median ventilatory nerve (MVN) originating at the $\mathrm{A} 3$ neuromere of the MTG. Signals were amplified using a differential alternating current amplifier (model 1700, A-M Systems) and digitized using a DigiData 1322A (Molecular Devices). Ventilation recordings were then displayed and recorded using AxoScope 9.0 software (Molecular Devices), and data were analyzed using Clampfit 9.0 (Molecular Devices). The rhythmic motor patterns shown throughout this study were of expiratory bursts, which we confirmed by observing that abdominal muscle contractions were in sync with electrical activity recorded from the MVN. Expiratory burst duration and cycle period data were generated by measuring expiratory bursts as indicated in Figure $2 b$. Expiratory bursts were measured every $5 \mathrm{~min}$ over the course of each experiment, and values from different preparations were averaged to obtain means \pm SE.

Preparation of potassium-sensitive microelectrodes. $\mathrm{K}^{+}$-sensitive microelectrodes were made from $1 \mathrm{~mm}$ diameter unfilamented capillary tubes (World Precision Instruments) that were cleaned with methanol (99.9\%) and dried on a hot plate before being pulled to form a low resistance (5-7 $\mathrm{M} \Omega$ ) tip. The inner glass surface of the microelectrodes was made hydrophobic by exposure to dichlorodimethylsilane (99\%) (Sigma-Aldrich) vapor while baking on a hot plate $\left(100^{\circ} \mathrm{C}\right)$ for $1 \mathrm{~h}$. The microelectrodes were allowed to cool and then filled at the tip with Potassium Ionophore I-Cocktail B (5\% valinomycin; Sigma-Aldrich) and backfilled with $500 \mathrm{~mm}$ KCl. Reference microelectrodes were made from $1 \mathrm{~mm}$ diameter filamented capillary tubes (World Precision Instruments) that were pulled to form a low resistance (5-7 M $\Omega$ ) tip and then filled with $3 \mathrm{M} \mathrm{KCl}$. Microelectrode tips were suspended in distilled water until experimentation.

Extracellular potassium recording. $\mathrm{K}^{+}$-sensitive and reference microelectrodes were connected to a $\mathrm{pH} /$ ion amplifier (Model 2000, A-M Systems). $\mathrm{A} \mathrm{K}^{+}$-sensitive and reference microelectrode pair were calibrated at room temperature $\left(\sim 21^{\circ} \mathrm{C}\right)$ using 15 and $150 \mathrm{~mm} \mathrm{KCl}$ solutions to obtain the voltage change, or "slope," which was required for determination of $\left[\mathrm{K}^{+}\right]_{\mathrm{o}}$ (in $\mathrm{mM}$ ) using the Nernst equation (Rodgers et al., 2007).

Pharmacological treatments. All chemicals were obtained from SigmaAldrich Canada and dissolved in standard locust saline in addition to a minimum amount of DMSO $(0.5 \mathrm{ml}$ per $100 \mathrm{ml}$ of saline; in control preparations as well) and bath applied to the semi-intact preparation. Each experiment was $1 \mathrm{~h}$ in duration. In all preparations the MTG was bathed in standard locust saline for $20 \mathrm{~min}$ before pharmacological treatment. To examine the effects of chemical anoxia on ventilatory motor pattern generation, $10^{-3}$ and $5 \times 10^{-4} \mathrm{M}$ doses of $\mathrm{NaN}_{3}$ were bath applied until $1 \mathrm{~min}$ after arrest of the ventilatory motor pattern and washed out with standard locust saline. Lower doses of $\mathrm{NaN}_{3}\left(10^{-4}\right.$ and $\left.10^{-5} \mathrm{M}\right)$ were bath applied for $40 \mathrm{~min}$. AICAR $\left(10^{-3} \mathrm{M}\right)$ and compound-C $\left(10^{-4} \mathrm{M}\right)$ were bath applied for $40 \mathrm{~min}$. A higher dose of AICAR $\left(10^{-2} \mathrm{M}\right)$ was bath applied for $20 \mathrm{~min}$, followed by $10^{-4} \mathrm{M}$ compound-C application for $20 \mathrm{~min}$. To investigate the effects of compound-C and glucose on the poststress motor pattern, $10^{-4} \mathrm{M}$ compound-C and $10^{-3} \mathrm{M}$ glucose were bath applied 10-12 min following recovery from $\mathrm{NaN}_{3}$-induced arrest for $\sim 20 \mathrm{~min}$. To examine the effects of AMPK activation and inhibition on ouabain-induced repetitive SD-like events, we bath applied either $10^{-2} \mathrm{M}$ AICAR or $10^{-4} \mathrm{M}$ compound-C alone for $15 \mathrm{~min}$, followed by either $10^{-2} \mathrm{M}$ AICAR or $10^{-4} \mathrm{M}$ compound-C in combination with $10^{-4} \mathrm{M}$ ouabain for 35 min. Compound-C $\left(10^{-4} \mathrm{M}\right)$ in combination with $10^{-4} \mathrm{M}$ ouabain was also bath applied following the initial ouabain-induced SD-like event. The time to the initial $\left[\mathrm{K}^{+}\right]_{\mathrm{o}}$ event was measured as the time from ouabain, AICAR/ ouabain. or compound-C /ouabain application to the inflection point of the first abrupt increase in $\left[\mathrm{K}^{+}\right]_{\text {o }}$.

Statistical analyses. Data were plotted using SigmaPlot 11.0 (SPSS) and are presented as the mean and SE. Statistical analyses were performed 
using SigmaStat 3.0 statistical analysis software (SPSS), and significant differences between means were determined using appropriate parametric tests. ANOVAs were used to determine significant differences among multiple groups, and the test used was chosen based on the number of subject factors and whether the analysis involved repeated measures. Post hoc Tukey tests were used to determine differences among two specific groups within the dataset. The terms "relative duration" and "relative period" used throughout this article refer to data normalized to initial duration or period values measured at $5 \mathrm{~min}$. Statistical comparisons were performed on the raw data using two-way repeated measures (RM)ANOVAs before generating relative data for display purposes. A $z$ test was used to test for significant differences between proportions. A 95\% confidence interval was used to determine significance.

\section{Results}

Energetic status affected time to succumb to coma and time to recover neural function

Locusts enter a coma during anoxia by immersion under water, and we have shown previously that vulnerability to coma, i.e., the length of time taken to enter a coma under anoxic conditions and to recover ventilatory rhythm generation upon reoxygenation, is modulated by cellular signaling pathways (Armstrong et al., 2009). To determine whether coma is modulated by nutrient status and the energy sensor AMPK, we examined vulnerability to coma by immersion under water in response to starvation, AMPK activation, and AMPK inhibition. Fed locusts immersed under water succumbed and entered a coma in $2.6 \mathrm{~min}$, and $4 \mathrm{~d}$ of starvation increased the time taken to enter a coma twofold to threefold (6.1 min) (Fig. 1a). We tested the idea that starvation might increase breath-holding capacity by increasing tracheal volume (Lease et al., 2006) and found that 3-4 d of starvation increased tracheal volume by $23 \%$ in adult locusts (from $0.38 \pm$ 0.02 to $0.47 \pm 0.03 \mathrm{ml} ; t$ test, $p=0.02$ ). After removal from water, ventilatory function recovered in fed locusts after $12.3 \mathrm{~min}$, and $4 \mathrm{~d}$ of starvation increased the time taken to recover ventilation to 16 min (Fig. 1b). AMPK activation or inhibition did not have a significant effect on time to succumb, but AMPK activation in starved locusts significantly increased the time to recover ventilation, and AMPK inhibition in fed locusts significantly decreased time to recover ventilation (Fig. 1). Notably, AMPK inhibition negated the effect of starvation on time to recover ventilation whereas AMPK activation potentiated it (Fig. 1b). Given that AMPK activation is necessary and sufficient to mimic the effects of starvation on time to recover rhythmic ventilatory movements observed in whole animals, we tested the influence of AMPK on ventilatory motor patterning in response to acute energy stress.

\section{Ventilatory motor patterning was altered before and after $\mathrm{NaN}_{3}$-induced coma}

As for mammalian cerebral SD coupled with metabolic compromise or anoxic depolarization, we presume that the likelihood and quality of recovery of ventilatory rhythm generation in the locust depend on the severity and duration of anoxia and energy deprivation. Here, we examined ventilatory burst durations and cycle periods following recovery from a $\mathrm{NaN}_{3}$-induced vCPG shutdown to determine whether acute energy stress results in an altered motor pattern or long-term changes to vCPG output (Fig. 2; supplemental Fig. 1, available at www.jneurosci.org as supplemental material). Perfusion of $10^{-3} \mathrm{M} \mathrm{NaN}_{3}$ induced vCPG arrest within $5 \mathrm{~min}$, and this coincided with an abrupt surge in $\left[\mathrm{K}^{+}\right]_{\mathrm{o}}$ (Fig. 2a,b). Control animals had consistent (unchanging) burst durations and periods over $1 \mathrm{~h}$ of standard saline perfusion (Fig. $2 c, d)$. Following recovery from $\mathrm{NaN}_{3}$-induced arrest, burst dura-

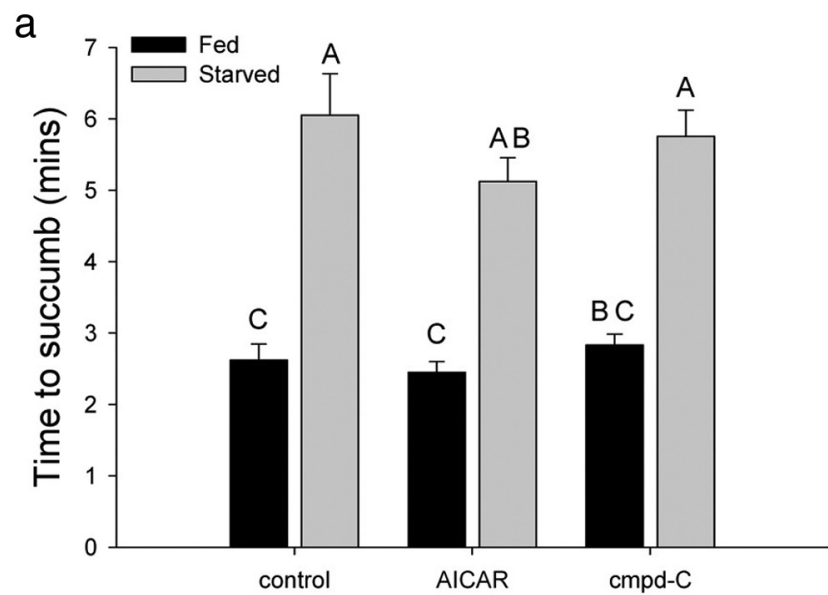

b

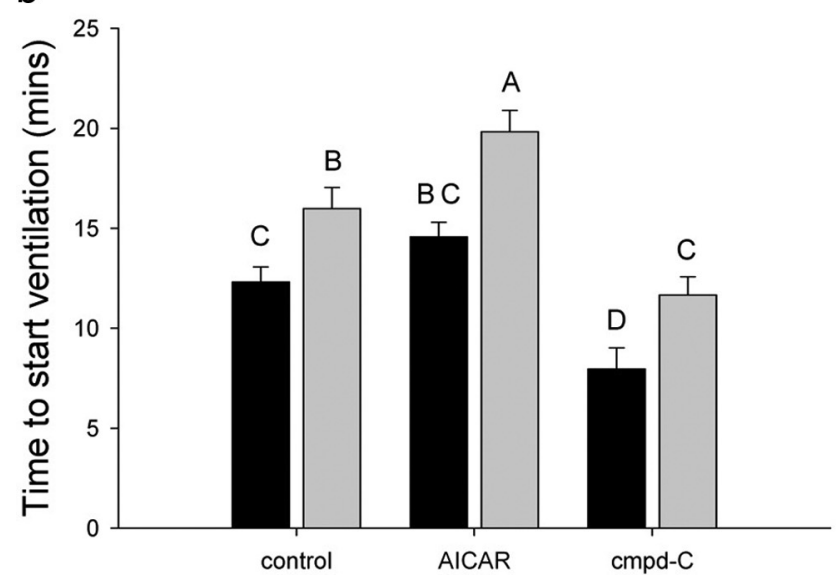

Figure 1. Manipulating energetic status by starvation affects locust vulnerability to anoxia by waterimmersion. $\boldsymbol{a}, \boldsymbol{b}, 0$ ne hour before submersion under water, fed and starved locusts received a 10 $\mu$ linjection of either $10^{-1} \mathrm{M}$ AICAR or $10^{-3} \mathrm{~m}$ compound-C (cmpd-C) into the hemocoel. Control locusts were injected with standard locust saline containing $0.5 \%$ DMSO. $a$, Four days of starvation increased the resistance of intact locusts to anoxia by increasing the time taken to enter coma. Time to succumb to coma was not significantly affected by manipulation of the AMPK pathway. $\boldsymbol{b}$, Starvation increased the time taken for ventilatory motor patterning to recover following anoxia. AMPK activation using AICAR significantly increased time to recover ventilation in starved locusts, and AMPK inhibition using compound-C significantly decreased time to recover ventilation in fed locusts. Sample sizes: control $\left.\right|_{\text {(fed,starved) }}=(9,9), \operatorname{AICAR}_{\text {(fed,starved) }}=(10,9), \mathrm{cmpd}_{\text {(fed,starved) }}=(10,10)$. Data plotted as mean \pm SEM. Data in columns with the same letter are not significantly different.

tions and periods gradually increased over time and deviated from the prestress motor pattern (Fig. $2 b, \mathrm{c}-d) . \mathrm{NaN}_{3}\left(10^{-3} \mathrm{M}\right.$ ) had a significant effect on relative burst durations and periods compared to control (two-way RM-ANOVAs, $p<0.001$ ) (Fig. $2 c, d)$. In contrast to the control values, relative burst durations and periods increased by $3.7 \pm 0.5$ and $1.6 \pm 0.2$, respectively, at $2 \mathrm{~min}$ following recovery and by $8.8 \pm 1.8$ and $3.5 \pm 0.7$, respectively, at $30 \mathrm{~min}$ following recovery (Fig. $2 c, d$ ).

$\mathrm{NaN}_{3}$ had a concentration-dependent effect on ventilatory motor patterning (supplemental Fig. 1, available at www. jneurosci.org as supplemental material). vCPG arrest and an associated surge in $\left[\mathrm{K}^{+}\right]_{\mathrm{o}}$ were induced by both $10^{-3} \mathrm{M}$ and $5 \times$ $10^{-4} \mathrm{M} \mathrm{NaN}_{3}$ (Fig. 2 and supplemental Fig. 1, available at www. jneurosci.org as supplemental material). Decreasing the dose to $5 \times 10^{-4} \mathrm{M} \mathrm{NaN}_{3}$ resulted in a longer time to $\mathrm{vCPG}$ arrest, and there was not a complete switch to the long duration and period motor pattern after recovery as seen in response to $10^{-3} \mathrm{M} \mathrm{NaN}_{3}$ (supplemental Fig. $1 a, b) . \mathrm{NaN}_{3}\left(5 \times 10^{-4} \mathrm{M}\right)$ significantly increased both the time to vCPG arrest and the time to subsequent 
recovery ( post hoc Tukey tests, $p<0.05$ ) (supplemental Fig. 1b). There was a strong and significant positive correlation between time to arrest of ventilatory motor pattern generation during $\mathrm{NaN}_{3}$ perfusion and time to subsequent recovery (Pearson product-moment correlation, $r=0.85, p<0.0001$ ) (supplemental Fig. 1c). Lower $\mathrm{NaN}_{3}$ doses $\left(10^{-4}\right.$ and $\left.10^{-5} \mathrm{M}\right)$ did not induce vCPG arrest, but there was a concentration-dependent effect on the initial response of the ventilatory motor pattern to $\mathrm{NaN}_{3}$ (supplemental Fig. 1di, dii). Cycle periods decreased within the first 5 min of $5 \times 10^{-4} \mathrm{M} \mathrm{NaN}_{3}$ perfusion, and this occurred to a lesser degree in response to $10^{-4} \mathrm{M} \mathrm{NaN}_{3}$. Following the initial response to $10^{-4} \mathrm{M} \mathrm{NaN}$, cycle periods returned to pre- $\mathrm{NaN}_{3}$ values after 30 min. $\mathrm{NaN}_{3}\left(10^{-5} \mathrm{M}\right)$ did not have a significant effect on ventilatory cycle periods ( post hoc Tukey tests, $p<0.05$ ) (supplemental Fig. 1di,dii). Ventilatory burst durations changed in a qualitatively similar way to cycle periods in response to the different $\mathrm{NaN}_{3}$ doses (Fig. 2c,d) so for clarity only cycle period data are presented here and below.

Cycle periods following recovery from $\mathrm{NaN}_{3}$-induced arrest gradually increased over time (Fig. 2b,d), and we tested whether these changes represented a controlled switch to slower ventilation, reflecting a reduction in metabolic demand or an inability to maintain a pattern. To determine whether the $\mathrm{vCPG}$ was capable of generating the prestress motor pattern, we increased the internal temperature of the preparation, a treatment that usually results in increased ventilatory frequency. Increasing the internal temperature $5^{\circ} \mathrm{C}$ following recovery from $\mathrm{NaN}_{3}$-induced arrest restored cycle periods to control values (supplemental Fig. 2, available at www.jneurosci.org as supplemental material).

AMPK activation mimicked the effects of $\mathrm{NaN}_{3}$ on ventilatory motor pattern behavior

AMPK is activated by cell stress, i.e., decreased energy status triggers an increase in AMPK activity. The initial response to $\mathrm{NaN}_{3}$ perfusion was a decrease in burst durations and periods before $\mathrm{NaN}_{3}$-induced arrest, followed by an increase in burst durations and periods after recovery (Fig. 2; supplemental Fig. 1). We tested whether AMPK activation using the AMPK activator AICAR would mimic the motor pattern changes induced by a $\mathrm{NaN}_{3}$ induced shutdown. AICAR $\left(10^{-2} \mathrm{M}\right)$ was bath applied in the absence of $\mathrm{NaN}_{3}$ to artificially signal decreased energy status, resulting in shortened ventilatory burst durations and periods after 2 min of perfusion (Fig. 3). After 10-20 min, AMPK activation using $10^{-2} \mathrm{M}$ AICAR had multiple effects on the ventilatory rhythm that can be divided into four distinct categories: (1) the
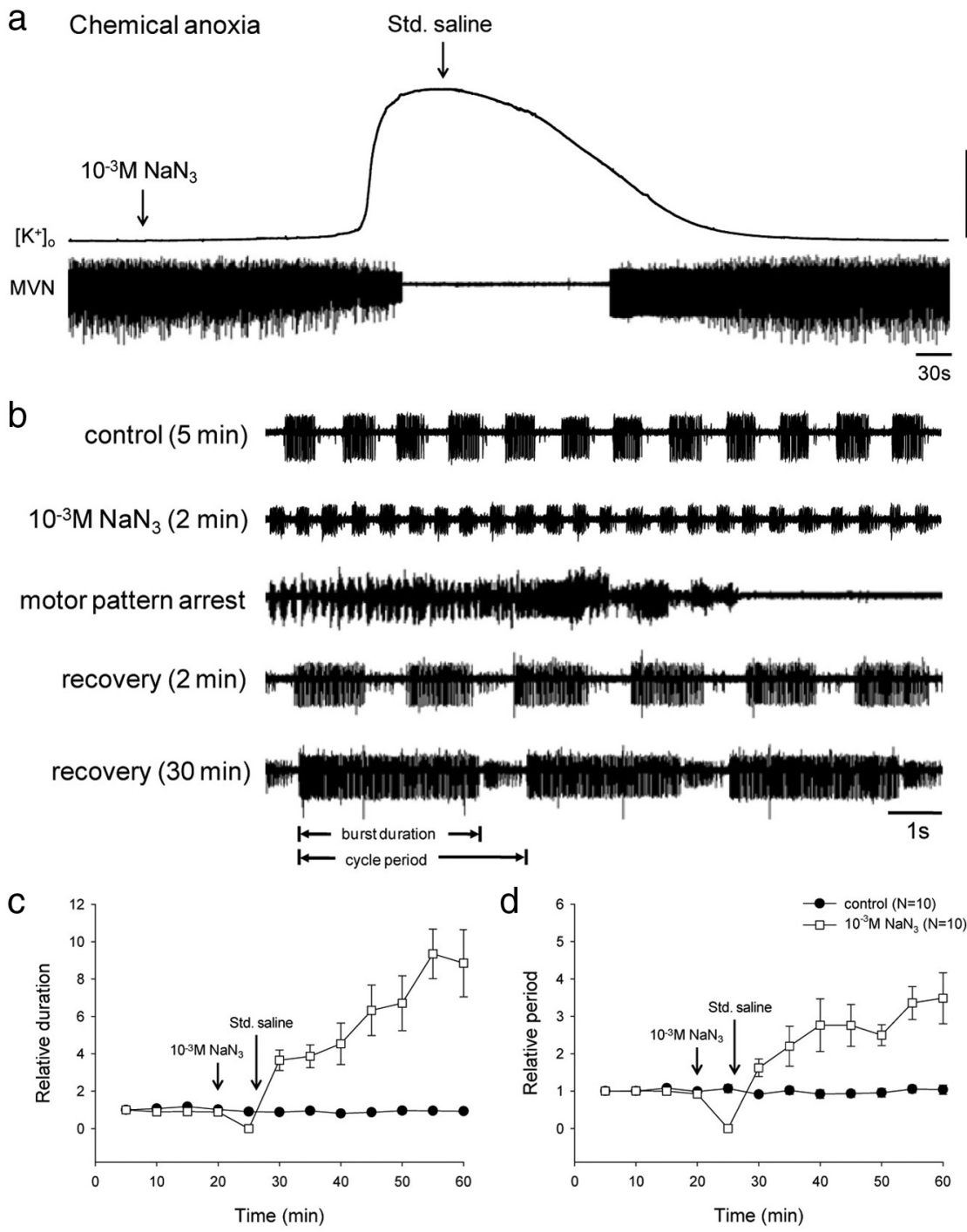

Figure 2. Duration and period of expiratory bursts following anoxia-induced vCPG arrest progressively increased over time. $\boldsymbol{a}$ Simultaneous recording of electrical activity from the MVN originating at the $A 3$ neuromere of the MTG and the $\left[\mathrm{K}^{+}\right]_{0}$ surrounding the vCPG. An abrupt rise in $\left[\mathrm{K}^{+}\right]_{0}$ was reliably triggered by $\mathrm{NaN}_{3}$ perfusion $\left(10^{-3} \mathrm{M} \mathrm{NaN} ; 3=10\right)$. Following 20 min of standard maximum value of $77 \pm 3 \mathrm{~mm}(\mathrm{~N}=10)$. $\left[\mathrm{K}^{+}\right]_{0}$ gradually decreased, and the motor pattern recovered upon perfusion of standard locust saline. $\boldsymbol{b}$, Expansions of extracellular electrical activity measured from the MVN of a single preparation before, during, and values at $2 \mathrm{~min}$ following recovery [recovery $(2 \mathrm{~min})$ ] or $30 \mathrm{~min}$ following recovery [recovery $(30 \mathrm{~min})$ ]. $\boldsymbol{c}, \boldsymbol{d}$, Relative duration (c) were 0 during $\mathrm{vCPG}$ arrest coinciding with the $\left[\mathrm{K}^{+}\right]_{0}$ event. Error bars represent SEM.

pre-AICAR motor pattern was replaced with continuous tonic activity; (2) the pre-AICAR motor pattern was replaced with unpatterned tonic activity or large amplitude expiratory bursts; (3) another long duration/long period rhythm was interspersed with the pre-AICAR motor pattern; and (4) the second long duration/ long period rhythm replaced the pre-AICAR rhythm, which became completely absent.

\section{Compound-C reversed the effects of AICAR and $\mathrm{NaN}_{3}$ on ventilatory motor patterning}

A lower dose of AICAR $\left(10^{-3} \mathrm{M}\right)$ was bath applied in nonstressed (control) preparations and had a significant effect on relative cycle periods (two-way RM-ANOVAs, $p<0.05$ ) (Fig. $4 a$ ). As with $10^{-2} \mathrm{M}$ AICAR, activation of AMPK using $10^{-3} \mathrm{M}$ AICAR did not induce vCPG shutdown or an abrupt surge in $\left[\mathrm{K}^{+}\right]_{\mathrm{o}}$, but 
a control (5 min)

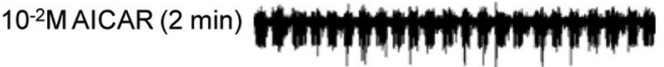
10-2M AICAR (10 min) 10-2M AICAR (20 min)

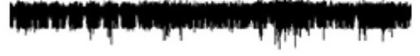

10-4 M cmpd-C (20 min)

C control (5 min)

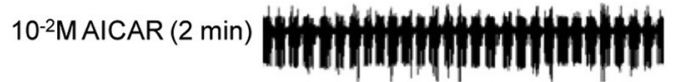

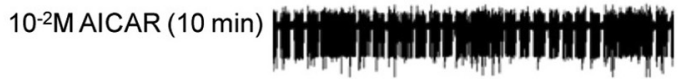
10-2M AICAR (20 min)

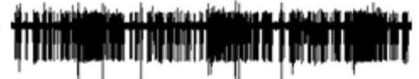
10-4 M cmpd-C (20 min) b $+1+1$

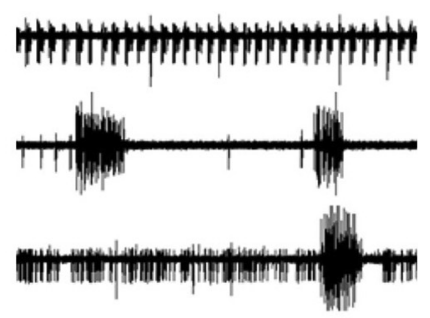

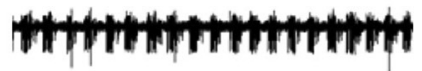

d

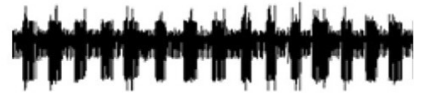

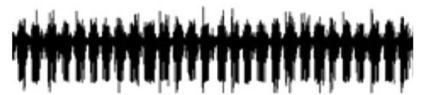
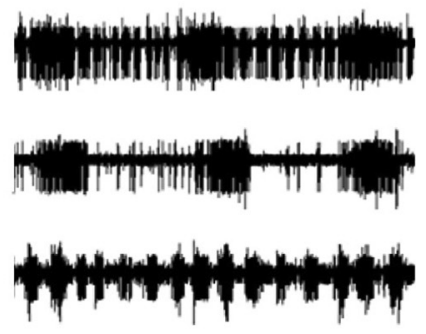

Figure 3. AMPKinhibition using compound-C reversed the effects of AICAR on the ventilatory motor pattern. Each panel ( $\boldsymbol{a}-\boldsymbol{d})$ shows motor pattern traces from an individual preparation. $\boldsymbol{a}-\boldsymbol{d}$, $\operatorname{AICAR}\left(10^{-2} \mathrm{M}\right)$ was bath applied in preparations for $20 \mathrm{~min}$, followed by bath application of $10^{-4} \mathrm{M}$ compound- $\mathrm{C}$ (" $\left.\mathrm{cmpd}-\mathrm{C}\right)$ for $20 \mathrm{~min}$. The label "control ( $\left.5 \mathrm{~min}\right)$ " indicates $5 \mathrm{~min}$ of standard locust saline perfusion, and "AICAR (2 min)," "AICAR (10 min)," and "AICAR (20 min)" indicate 2, 10, and 20 min of $10^{-2}$ M AICAR perfusion, respectively. The label " $\mathrm{cmpd}-\mathrm{C}(20 \mathrm{~min})$ " indicates $20 \mathrm{~min}$ of $10^{-4} \mathrm{M}$ compound-C perfusion. AICAR $\left(10^{-2} \mathrm{M}\right)$ induced an immediate decrease in burst durations and periods within $1-2 \mathrm{~min}$, and this was followed by multiple effects on the ventilatory rhythm, some resembling the recovered motor pattern following $\mathrm{NaN}_{3}$-induced arrest: $\boldsymbol{a}$, Continuous tonic activity $(N=1), \boldsymbol{b}$, Loss of the pre-AICAR motor pattern and unpatterned, high amplitude tonic activity $(N=2), c$, Another long duration/long period rhythm interspersed with the initial motor pattern [similar to the effect of $5 \times 10^{-4} \mathrm{M} \mathrm{NaN}{ }_{3}$ shown in supplemental Fig. 1a, "recovery $(30 \mathrm{~min})$ "] $(N=4)$. $\boldsymbol{d}$, The second long duration/long period rhythm replaced the initial rhythm [similar to the effect of $10^{-3} \mathrm{M} \mathrm{NaN} \mathrm{N}_{3}$ shown in Fig. $2 b$, "recovery $\left.(2 \mathrm{~min})^{\prime \prime}\right](N=3)$. Regardless of the effect of AICAR, $10^{-4} \mathrm{M}$ compound-C returned the rhythm to pre-AICAR duration and period values.

shortened cycle periods by $0.5 \pm 0.03$ within 5 min relative to pre-AICAR values (Fig. 4a). Bath application of $10^{-4} \mathrm{M}$ compound-C in nonstressed preparations had no significant effect on cycle periods (two-way RM-ANOVAs, $p<0.05$ ). Relative periods in preparations treated with $10^{-3} \mathrm{M}$ AICAR were significantly different than those in control preparations and those treated with $10^{-4} \mathrm{M}$ compound-C after 5 min of perfusion (post hoc Tukey tests, $p<0.05$ ) (Fig. $4 a$ ).

AMPK inhibition using $10^{-4} \mathrm{M}$ compound-C did not alter ventilatory motor patterning when applied in nonstressed preparations but had a profound effect when applied in preparations initially treated with either AICAR or $\mathrm{NaN}_{3}$ (Figs. 3, 4b,c). After $10^{-2} \mathrm{M}$ AICAR was bath applied for $20 \mathrm{~min}$, we bath applied $10^{-4}$ $\mathrm{M}$ compound-C for $20 \mathrm{~min}$ (Fig. 3). Regardless of the effect of AICAR, $10^{-4} \mathrm{M}$ compound-C partially restored cycle periods to pre-AICAR values (Figs. 3, 4b). This restorative effect was seen when compound-C was applied alone (dissolved in standard locust saline) or in combination with $10^{-2} \mathrm{M}$ AICAR (both drugs dissolved in standard locust saline; data not shown), and the effects of AICAR on motor patterning could also be reversed by saline washout (data not shown). $\operatorname{AICAR}\left(10^{-2} \mathrm{M}\right)$ significantly shortened cycle periods by $0.4 \pm 0.05$ relative to preAICAR values within $5 \mathrm{~min}$, and $10^{-4} \mathrm{M}$ compound-C subsequently significantly increased periods to near-control values ( post hoc Tukey tests, $p<0.05$ ) (Fig. 4b).

Because compound-C reversed the effects of AICAR, we tested whether blocking AMPK activation would have a similar effect following $\mathrm{NaN}_{3}$-induced arrest. We also tested the role of energy status by adding glucose to the saline. Following $\mathrm{NaN}_{3}$ induced arrest, burst durations and periods gradually increased over time (Fig. $2 b-d$ ). We bath applied either $10^{-4}$ $\mathrm{M}$ compound-C or $10^{-3} \mathrm{M}$ glucose $10-15$ min following recovery from $\mathrm{NaN}_{3}$ induced arrest to determine the effect of these treatments on the recovered motor pattern (Fig. 4c). Perfusion of $10^{-4} \mathrm{M}$ compound-C following recovery from $\mathrm{NaN}_{3}$-induced arrest decreased cycle periods to near-control values by $20 \mathrm{~min}$ (Fig. 4c). Perfusion of $10^{-3} \mathrm{M}$ glucose mimicked the effects of compound-C on the motor pattern and returned ventilatory periods to near-control values (Fig. $4 c$ ). The presence of glucose could mimic the effects of AMPK inhibition by sending a signal that energy state is not compromised. In preparations treated with either $10^{-4} \mathrm{M}$ compound-C or $10^{-3} \mathrm{M}$ glucose following $\mathrm{NaN}_{3}$-induced $\mathrm{vCPG}$ arrest, relative periods were not significantly different than control values after $10 \mathrm{~min}$ of application (post hoc Tukey tests, $p<$ 0.05) (Fig. 4c).

AMPK inhibition suppressed ouabaininduced SD-like events

There were striking similarities in this study between the ventilatory motor pattern during AMPK activation using AICAR (Fig. 3) and the motor pattern following recovery from $\mathrm{NaN}_{3}$-induced $\mathrm{VCPG}$ arrest and the associated SDlike event (Fig. 2; supplemental Fig. 1). In addition, compound-C reversed the effects of both AICAR and $\mathrm{NaN}_{3}$ by returning ventilatory cycle periods to near-control values (Figs. 3, 4b,c). Given these results, we hypothesized that SD-like events in the locust induced by a milder stress such as impairment of ionic homeostasis using ouabain may be modulated by AMPK activation. We found that susceptibility to ouabain-induced SD-like events was increased by AMPK activation and decreased by AMPK inhibition (see Figs. 5 and 6 for descriptive data and Fig. 7 for corresponding quantitative analysis below).

Continuous bath-application of $10^{-4} \mathrm{M}$ ouabain induces repetitive vCPG arrest, with each period of electrical silence coinciding with an abrupt surge in $\left[\mathrm{K}^{+}\right]_{\mathrm{o}}$ (Rodgers et al., 2007, 2009) (Fig. $5 a$ ). Preparations treated with $10^{-4} \mathrm{M}$ ouabain alone represent "control" preparations (Fig. 5a). All control preparations 

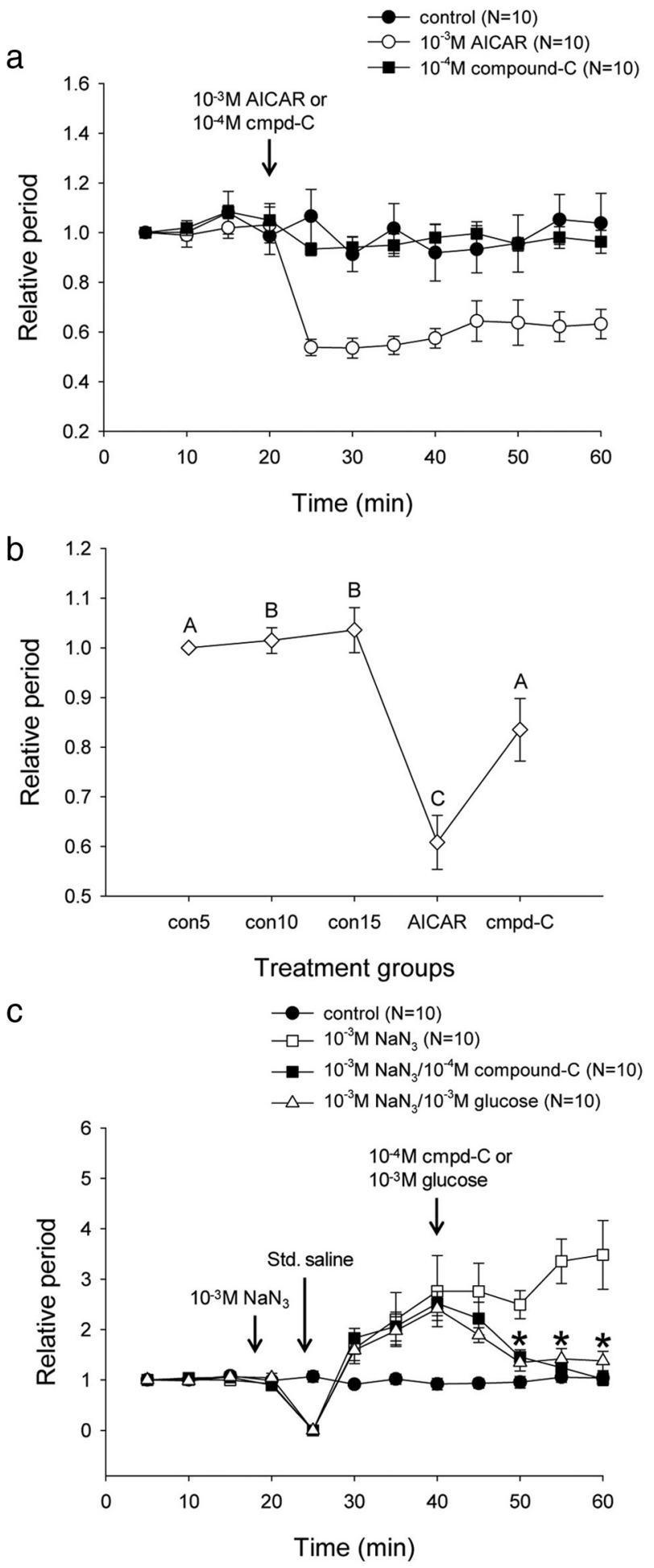

Figure 4. AMPK inhibition using compound-C reversed the effects of AICAR and $\mathrm{NaN}_{3}$ on ventilatory motor patterning by returning ventilatory cycle periods to control values, and glucose mimicked the effects of compound-C. $\boldsymbol{a}$, Relative to pre-AICAR values, AMPK activation using $10^{-3} \mathrm{M}$ AICAR significantly shortened cycle periods, and inhibition of AMPK using $10^{-4}$ $M$ compound- $C$ (cmpd-C) had no effect in nonstressed (control) preparations. b, AMPK inhibition using compound-C reversed the effects of AICAR on the ventilatory motor pattern. The labels "con5," "con10," and "con15" represent 5, 10, and 15 min of standard locust saline perfusion. Following $20 \mathrm{~min}$ of standard locust saline perfusion, perfusion of $10^{-2} \mathrm{M}$ AICAR for 5 min significantly shortened cycle periods relative to pre-AICAR values $(N=10)$. Following 20 min of $10^{-2} \mathrm{M}$ AICAR perfusion, $10^{-4} \mathrm{M}$ compound- $C$ was perfused for $20 \mathrm{~min}$. Cycle periods partially returned to control values following perfusion of compound-C for $20 \min (N=10)$. Data in columns with the same letter are not significantly different. $C, \mathrm{NaN}_{3}\left(10^{-3} \mathrm{M}\right)$ was had at least one SD-like event over the course of ouabain treatment. The time to onset of the initial ouabain-induced SD-like $\left[\mathrm{K}^{+}\right]_{\mathrm{o}}$ event was $12.2 \pm 1.4 \mathrm{~min}$, and there were $3.1 \pm 0.4 \mathrm{SD}$-like events on average within $35 \mathrm{~min}$ (see Fig. 7 below for quantitative analyses). Unlike the effect of $\mathrm{NaN}_{3}$ or AICAR, recurring SD induced by $\mathrm{Na} / \mathrm{K}$ pump inhibition using ouabain was not associated with changes in ventilatory motor patterning. In comparison to the pre-ouabain motor pattern, ventilatory cycle periods were not affected by ouabain-induced SD following 1,2 , or 3 consecutive SD-like events $(N=10$; one-way ANOVA, $p=$ 0.415; data not shown but see Fig. 5ai,ii,iii). SD can also be induced by injection of high $\left[\mathrm{K}^{+}\right]$into the neuropil (Armstrong et al., 2009). We reanalyzed some of the data presented in that paper (Armstrong et al., 2009) to determine the effect of $\mathrm{K}^{+}$-induced SD on motor patterning and found that there was no difference in relative period of the motor pattern at recovery $(1.13 \pm 0.07$ of pre-SD values; not significant) and 20 min after recovery $(0.8 \pm$ 0.05 of pre-SD values; not significant $)(N=10$; Mann-Whitney rank sum tests). This supports the conclusion from the ouabain treatment that SD in the absence of metabolic stress does not affect the motor pattern.

We pretreated preparations by bath applying either $10^{-2} \mathrm{M}$ AICAR or $10^{-4} \mathrm{M}$ compound-C for $15 \mathrm{~min}$, followed by bath application of either $10^{-2} \mathrm{M}$ AICAR or $10^{-4} \mathrm{M}$ compound-C in combination with $10^{-4} \mathrm{M}$ ouabain for $35 \mathrm{~min}$ (Fig. $5 b, c$ ). Ouabain-induced recurring SD-like events were exacerbated by $10^{-2} \mathrm{M}$ AICAR and suppressed by $10^{-4} \mathrm{M}$ compound-C (Fig. $5 b, c$; see Fig. 7 below for quantitative analyses). Pretreatment with $10^{-2} \mathrm{M}$ AICAR caused a $13.5 \pm 1.8 \mathrm{~mm}$ increase in $\left[\mathrm{K}^{+}\right]$。 and had effects on the ventilatory motor pattern similar to those seen in Figure 3 (Fig. 5bi,ii,iii). An examination of the ventilatory motor pattern following multiple ouabain-induced SD-like events revealed a complete switch to a long duration and long period motor pattern when AICAR was bath applied in combination with ouabain (Fig. 5bi,ii,iii). In 70\% (7/10) of preparations, $10^{-4} \mathrm{M}$ compound-C treatment completely abolished ouabain-induced SD-like events (Fig. $5 c$; see Fig. 7 below for quantitative analyses).

\section{Following initiation of locust SD, AMPK inhibition aborted subsequent ouabain-induced SD-like events}

Although AMPK inhibition resulted in complete suppression of ouabain-induced SD-like events in $70 \%$ of preparations, delayed SD-like events were elicited in the remaining $30 \%$ of preparations. There was an interesting effect of compound-C in these preparations in that the abrupt ouabain-induced increases in $\left[\mathrm{K}^{+}\right]_{\mathrm{o}}$ were not accompanied by electrical silence or $\mathrm{vCPG}$ arrest (Fig. 6a). Surprisingly, when compound-C was bath applied in combination with ouabain, ventilatory motor pattern generation continued during ouabain-induced SD-like events, where $\left[\mathrm{K}^{+}\right]_{\mathrm{o}}$ increased to around the same amplitude as in control preparations (compound-C, 55-65 mM; control, 60-70 mM); however, it should be noted that $\left[\mathrm{K}^{+}\right]_{\mathrm{o}}$ events were shorter in duration. Thus, compound-C not only delayed the onset and thus de-

$\leftarrow$

perfused in preparations until 1 min following arrest of ventilatory motor pattern generation, at which point preparations were allowed to recover in standard locust saline (Std. saline). Either $10^{-4} \mathrm{M}$ compound-C or $10^{-3} \mathrm{M}$ glucose was bath applied $10-15 \mathrm{~min}$ following recovery from $\mathrm{NaN}_{3}$-induced vCPG arrest. There were significant effects of both compound- $\mathrm{C}$ and glucose on cycle periods which were not significantly different than control values after perfusion for 10 min. Asterisks indicate significantly different cycle periods compared to preparations that recovered from $\mathrm{NaN}_{3}$-induced vCPG arrest in standard locust saline. Error bars represent SEM. 
a

\section{Ouabain (control)}

$\left[\mathrm{K}^{+}\right]_{\mathrm{o}}$

$10^{-4} \mathrm{M}$ ouabain

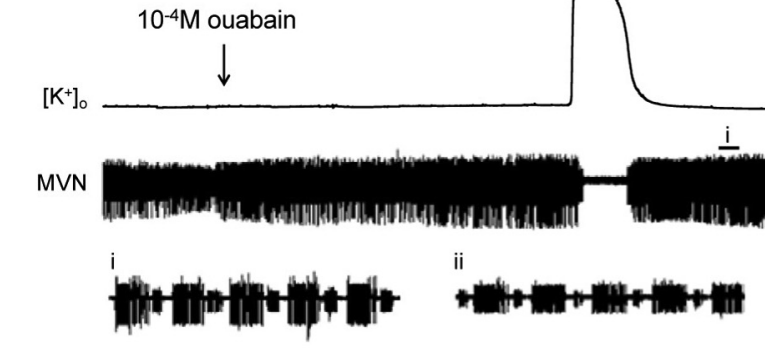

b

Ouabain + AICAR

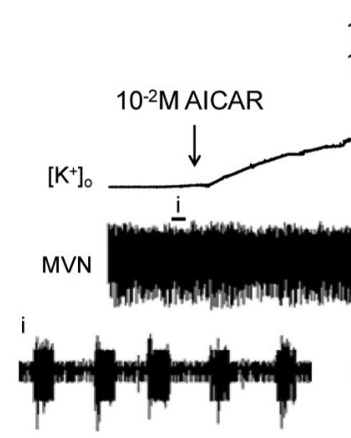

$10^{-4} \mathrm{M}$ ouabain/ 10-2M AICAR
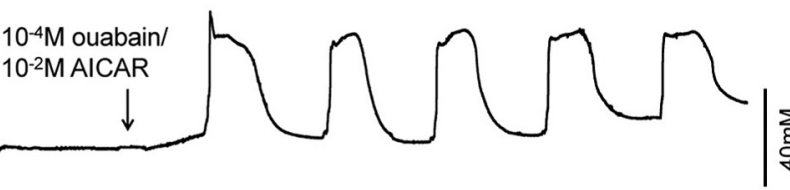

ii
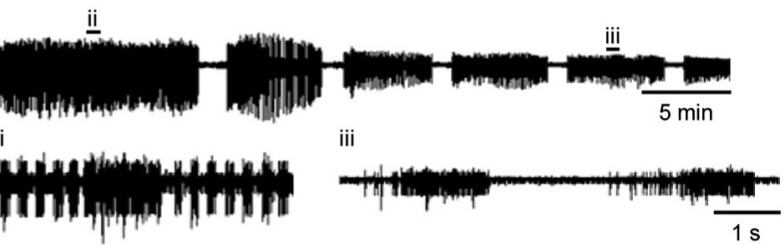

C

Ouabain + compound-C

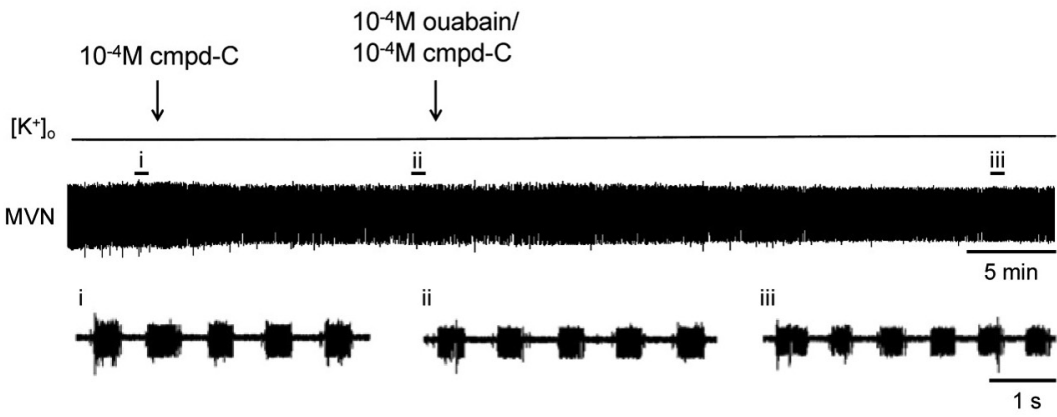

Figure 5. AMPK inhibition suppressed ouabain-induced spreading depression. Each panel $(\boldsymbol{a}-\boldsymbol{c})$ shows a representative experiment from an individual preparation. $\boldsymbol{a}-\boldsymbol{c}$, Simultaneous recording of electrical activity from median ventilatory nerve originating at the A3 neuromere of the MTG and the extracellular potassium concentration surrounding the VCPG. $\boldsymbol{a}$, 0uabain-induced recurring SD-like events in the locust MTG. Following $20 \mathrm{~min}$ of standard locust saline bath-application, $10^{-4} \mathrm{M}$ ouabain was bath applied for $35 \mathrm{~min}$. Ouabain $\left(10^{-4} \mathrm{M}\right)$ induced repetitive abrupt surges in $\left[\mathrm{K}^{+}\right]_{0}$ where the rise and fall of $\left[\mathrm{K}^{+}\right]_{0}$ were associated with arrest and recovery, respectively, of ventilatory motor pattern generation $(N=10)$. Ouabain $\left(10^{-4} \mathrm{M}\right)$ initiated repetitive SD-like events at $\sim 12$ min of application and induced $\sim 3$ SD-like events on average. One hundred percent of preparations had at least one SD-like event within $35 \mathrm{~min}$ of application. The expansions $(\boldsymbol{i}, \mathbf{i i}$, iii) show the motor pattern trace following each SD-like event in control (ouabain alone) preparations. SD induced by $\mathrm{Na}^{+} / \mathrm{K}^{+}$-ATPase inhibition did not influence the ventilatory motor pattern. $\boldsymbol{b}, \boldsymbol{c}$, Following $20 \mathrm{~min}$ of standard locust saline bath-application, preparations were pretreated with either $10^{-2} \mathrm{M} \mathrm{AICAR}$ (b) or $10^{-4} \mathrm{M}$ compound-C ("cmpd-C") (c) for $15 \mathrm{~min}$. AICAR $\left(10^{-2} \mathrm{M}\right)$ or compound-C $\left(10^{-4} \mathrm{M}\right)$ were then bath applied in combination with ouabain $\left(10^{-4} \mathrm{M}\right)$ for $35 \mathrm{~min}$. Expansions show the motor pattern trace at different time points: (i) before pretreatment; (ii) after 15 min of AICAR or compound-C pretreatment; and (iii) after bath application of ouabain in combination with AICAR or compound-C for 25-35 min. AMPK activation using AICAR increased the propensity for ouabain-induced SD-like events $(\boldsymbol{b} ; N=10)$ and AMPK inhibition using compound-C suppressed, ouabain-induced SD-like events $(\boldsymbol{c} ; N=10)$.

ouabain directly following the initial ouabain-induced SD-like event (Fig. 6b). As a result of compound-C introduction into preparations following SD onset, subsequent $\left[\mathrm{K}^{+}\right]_{\mathrm{o}}$ increases were substantially decreased in amplitude and duration compared to those in control preparations, and these muted $\left[\mathrm{K}^{+}\right]_{\mathrm{o}}$ surges did not coincide with electrical silence or vCPG arrest (Fig. 6b).

\section{Effects of AMPK activation and} inhibition on ouabain-induced

\section{SD-like events}

AICAR $\left(10^{-2} \mathrm{M}\right)$ significantly decreased the time to onset of SD-like events and significantly increased the number of SDlike events compared to control preparations and to those treated with $10^{-4} \mathrm{M}$ compound-C ( post hoc Tukey tests, $p<$ 0.05) (Fig. $7 a-c$ ). Compared to control preparations and those treated with $10^{-2}$ M AICAR, AMPK inhibition using $10^{-4} \mathrm{M}$ compound-C significantly reduced the proportion of preparations having at least one SD-like event ( $z$ test, $z=3.027, p=$ 0.002) (Fig. 7a). In the 3 of 10 preparations that had at least one SD-like event, $10^{-4} \mathrm{M}$ compound-C significantly delayed the time to onset of ouabaininduced SD-like events (post hoc Tukey tests, $p<0.05$ ) (Fig. 6a, 7b). Preparations treated with $10^{-4} \mathrm{M}$ compound-C also had significantly fewer SD-like events compared to preparations treated with $10^{-2}$ M AICAR ( post hoc Tukey tests, $p<$ 0.05 ) but not compared to control preparations, likely because of the small sample size (Fig. $7 c$ ). The duration of the initial SD-like event was also affected by AMPK manipulation; preparations treated with $10^{-2} \mathrm{M}$ AICAR had significantly longer duration $\left[\mathrm{K}^{+}\right]_{\mathrm{o}}$ surges compared to control and compound-C-treated preparations ( post hoc Tukey tests, $p<0.05$ ) (Fig. $7 d$ ). A possible explanation for the changes in SD-like event duration was that the rate of $\left[\mathrm{K}^{+}\right]_{\mathrm{o}}$ clearance was profoundly affected by pharmacological manipulation of AMPK (Fig. 7e). Preparations treated with AICAR had significantly decreased rates of $\left[\mathrm{K}^{+}\right]_{\mathrm{o}}$ clearance measured from the first ouabain-induced SD-like event compared to control and compound-C rates (top slopes: AICAR creased the number of ouabain-induced SD-like events in these preparations (see Fig. 7 below for quantitative analyses), but also prevented shutdown of neuronal activity (Fig. 6a), an important characteristic of SD-like events in both locust MTG and mammalian cerebral cortical tissue. In a separate set of experiments $(N=10)$, we induced SD-like events using $10^{-4} \mathrm{M}$ ouabain in exactly the same fashion as in control preparations, but we then bath applied $10^{-4} \mathrm{M}$ compound-C in combination with $10^{-4} \mathrm{M}$
$(N=10),-0.001 \pm 0.002 \mathrm{~mm} / \mathrm{s}$; control $(N=10),-0.5 \pm 0.1$ $\mathrm{mm} / \mathrm{s}$; compound-C $(N=3),-0.6 \pm 0.4 \mathrm{~mm} / \mathrm{s}$; down slopes: AICAR $(N=10),-0.3 \pm 0.04 \mathrm{~mm} / \mathrm{s} ;$ control $(N=10)$, $-1.3 \pm 0.1 \mathrm{~mm} / \mathrm{s} ;$ compound-C $(N=3),-1.5 \pm 0.5 \mathrm{~mm} / \mathrm{s}$; post hoc Tukey tests, $p<0.05)$. Preparations treated with compound-C had significantly increased rates of $\left[\mathrm{K}^{+}\right]_{\mathrm{o}}$ clearance compared to control and AICAR rates (post hoc Tukey tests, $p<0.05)$. 


\section{Discussion}

To cope with variable environments and to compensate for physiological dysfunction, neural circuits must be able to respond appropriately to metabolic stress. Despite much investigation of how anoxia and, more recently, the metabolic sensor, AMPK affect the biochemical economy of neurons, there is little information on how they might affect long-term neural circuit operation or whether such effects might be adaptive. We explored these issues using a locust model circuit and show for the first time that AMPK can modulate motor patterning in response to transient mitochondrial shutdown. Mitochondrial shutdown generated a coma associated with SD as well as the AMPK signal. We were able to dissociate these events and show that SD alone had no long-lasting effect on motor patterning but that AMPK was responsible for the changes in patterning. Moreover, AMPK activation did not induce a coma or SD, but the AMPK signal rendered the system more susceptible to $\mathrm{SD}$, which is important because of the involvement of SD in the etiology of human disorders such as migraine and stroke. SDlike events in the locust ventilatory neuropile share most of the major characteristics of SD in mammalian cortical tissue, including loss of ion homeostasis and electrical activity that spreads across tissue (see Rodgers et al., 2010, for a more thorough comparison). These results are discussed in more detail below.

Suffocation by immersion under water caused locusts to enter a coma, and both the time taken to succumb and the time to start ventilating upon return to normal $\mathrm{O}_{2}$ conditions were increased in starved locusts. Increased tracheal volume might have increased the time taken to succumb, as dehydration caused by starvation could have increased the volume of air in the tracheae, and more $\mathrm{O}_{2}$ in tracheae would take longer to deplete (Lease et al., 2006). We confirmed this in a separate analysis where we found that tracheal volume increased by $23 \%$ in starved adult locusts. It is also probable that metabolic rate suppression as a result of stress would contribute to increasing time to succumb (Staples and Buck, 2009). Thus, the large effect of tracheal volume and metabolic rate changes would explain why we did not detect more subtle effects of AICAR and compound-C on time to succumb. The time to start ventilating was increased by AMPK activation and decreased by AMPK inhibition, indicating that AMPK was sufficient and necessary for the effect of starvation. Given that the vulnerability of whole animals to anoxia induced in this ecologically relevant manner was modulated both by nutrient status and by manipulating the AMPK pathway, we determined whether acute metabolic stress and AMPK modulate the operation of an important circuit in the locust CNS, the ventilatory central pattern generator.

Long-term effects of chemical hypoxia induced by $\mathrm{NaN}_{3}$ on the central pattern generator controlling swim motor patterns of tadpole (Xenopus laevis) larvae were recently demonstrated (Robertson et al., 2010). We showed that chemical anoxia using $\mathrm{NaN}_{3}$ induced SD and temporary coma that were associated with profound changes in ventilatory motor pattern generation in locusts. Before coma and SD the initial response to $\mathrm{NaN}_{3}$ was a rapid rhythm, and this change was concentration dependent. $\mathrm{NaN}_{3}\left(10^{-3}\right.$ and $5 \times$ $10^{-4} \mathrm{M}$ ) induced vCPG arrest and an associated SD-like event, and the time to vCPG arrest was also concentration dependent. In a previous study, early motor pattern arrest in response to hyperthermia was correlated with a longer time to recovery when temperature returned to normal levels (Rodgers et al., 2007). We found a similar tradeoff in this study such that early vCPG arrest induced by $\mathrm{NaN}_{3}$ was associated with shorter times to recovery. We suggest that decreased metabolic demand afforded by coma is advantageous by conserving energy. Following SD and coma induced by $10^{-3} \mathrm{M}$ $\mathrm{NaN}_{3}$, the motor pattern recovered and deviated from the pre- $\mathrm{NaN}_{3}$ motor pattern, and this change was not as robust in response to $5 \times$ $10^{-4} \mathrm{M} \mathrm{NaN}_{3}$. Ventilatory burst durations and periods increased over time, in effect reducing motor pattern frequency. AMPK activation using AICAR did not induce coma or SD but caused the ventilatory rhythm to initially speed up and then had multidimensional effects at a high dose $\left(10^{-2} \mathrm{M}\right)$, some mimicking the effect of $\mathrm{NaN}_{3}$ in reducing motor pattern frequency. Since $\mathrm{NaN}_{3}$ is known to increase AMPK activity in other cell types (Jing and Ismail-Beigi, 2007; Guan et al., 2008; Kréneisz et al., 2009) we suggest that AMPK could be activated in the locust ventilatory neuropile in response to $\mathrm{NaN}_{3}$. AMPK activation can occur via different mechanisms (Hardie and Hawley, 2001; Lindsley and Rutter, 2004; Kodiha et al., 2007), and it is likely that AMPK was activated through different pathways in response to $\mathrm{NaN}_{3}$ and AICAR. Given that AICAR induced rhythm changes without inducing $\mathrm{SD}$, we conclude that 
a
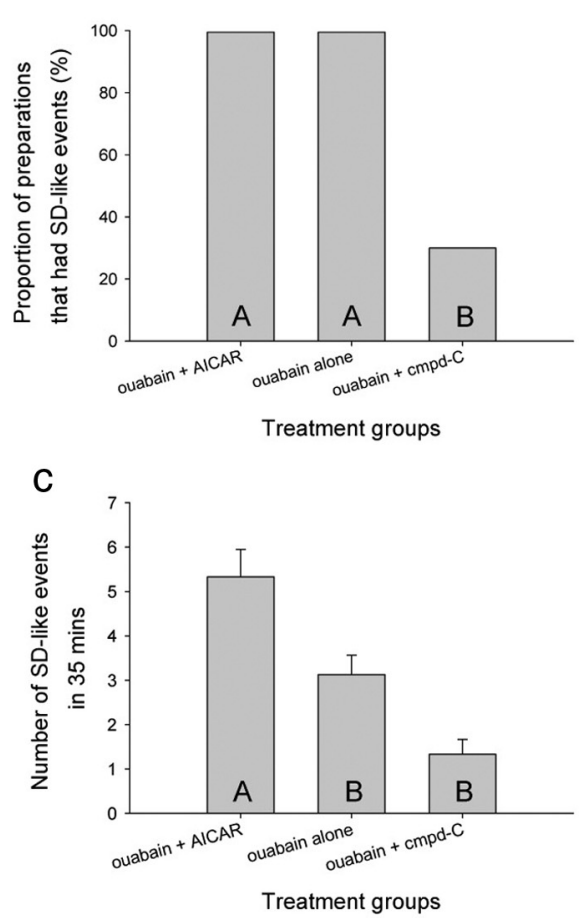

e

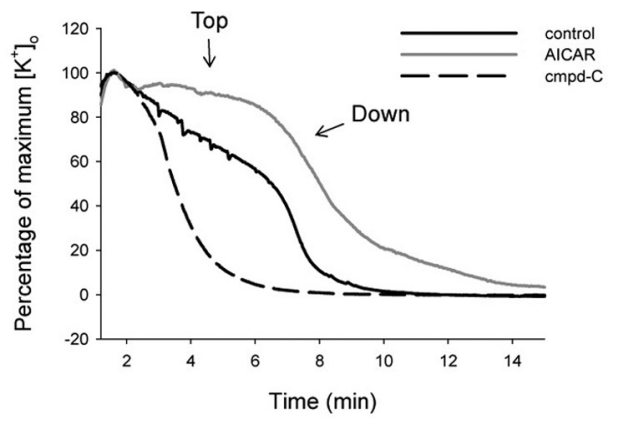

Figure 7. Effects of AMPK activation and inhibition on ouabain-induced SD. $a$, AMPK inhibition resulted in a 70\% decrease in the number of preparations having at least one ouabain-induced SD-like event. $\boldsymbol{b}$, Time to onset of ouabain-induced SD-like events was significantly decreased by AMPK activation and significantly increased by AMPK inhibition. Significant treatment effects were found (oneway ANOVA, $p<0.001$; control and AICAR, $N=10$; compound-C, $N=3$ ). $c$, AMPK activation also increased the number of SD-like events compared to control preparations and those treated with $10^{-4} \mathrm{M}$ compound- $\mathrm{C}(\mathrm{cmpd}-\mathrm{C})$, and significant effects of treatment were found (one-way ANOVA, $p=0.001$; control and AICAR, $N=10$; compound- $C, N=3$ ). Control preparations and those treated with compound- $C$ were not significantly different, likely because of the small sample size as a result of the low proportion of preparations treated with compound- $C$ that had at least one SD-like event. $\boldsymbol{d}$, AMPK activation significantly increased the duration of the initial ouabain-induced SD-like event, whereas AMPK inhibition significantly decreased SD-like event duration (one-way ANOVA, $p=0.001$; control and AICAR, $N=10$; compound- $C, N=3$ ).e, Overlay of individual $\left[\mathrm{K}^{+}\right]_{0}$ surges induced by ouabain in a control preparation (Fig. $5 a$ ), a preparation treated with AICAR (Fig. $5 b$ ), and a preparation treated with compound-C (Fig. 6a) to illustrate that on average AICAR decreases both phases ("Top" slope and "Down" slope) of the rate of $\left[\mathrm{K}^{+}\right]_{0}$ clearance, whereas compound-C has a tendency to increase rates of $\left[\mathrm{K}^{+}\right]_{0}$ clearance (see Results for means and SE). Traces were scaled to $100 \%$ amplitude from baseline to the peak $\left[\mathrm{K}^{+}\right]_{0}$ to aid comparison. Letters in histogram bars represent statistical groupings, whereby bars with different letters are significantly different using a post hoc Tukey test $(p<0.05)$. Error bars represent SEM.

AMPK is sufficient for the motor pattern changes induced by chemical anoxia. AMPK inhibition using compound-C reversed the effects of AICAR and $\mathrm{NaN}_{3}$ by returning ventilatory burst durations and periods to control values. Because compound-C is a well known selective and ATP-competitive inhibitor of AMPK (Zhou et al., 2001; Fediuc et al., 2006), this indicates that AMPK is necessary for the switch to a slow rhythm.

Of particular significance was that the motor pattern changes induced by AICAR were not dependent on CNS shutdown and the generation of SD. Alternatively, CNS shutdown and the generation of SD did not necessarily induce the motor pattern changes that we observed in response to $\mathrm{NaN}_{3}$ or AICAR. During repetitive SD induced by ouabain alone (Fig. $5 a$ ), the motor pattern remained unchanged following up to three $\left[\mathrm{K}^{+}\right]_{\mathrm{o}}$ surges. This demonstrates that $\mathrm{SD}$ generated by a relatively mild stress such as ouabain was not sufficient to cause the motor pattern changes induced by AMPK activation or metabolic stress such as anoxia. We further demonstrated this by reporting that motor pattern changes are not associated with high $\left[\mathrm{K}^{+}\right]$-induced SD. However AMPK activation increased the propensity for and severity of ouabain-induced SD-like events in the locust. We conclude that SD alone did not influence AMPK activity, but AMPK activity strongly influenced susceptibility to SD.

We presume that AMPK activation exacerbated SD-like events in the locust by suppressing energy-requiring processes, thereby affecting the electrochemical gradient. AMPK activation caused an increase in $\left[\mathrm{K}^{+}\right]_{\mathrm{o}}$ levels $(13.5 \pm 1.8 \mathrm{~mm})$ during pretreatment with AICAR. This may be caused by inhibition of $\mathrm{Na}^{+} / \mathrm{K}^{+}$-ATPase complexes within the MTG, as AMPK activation has been shown to reduce $\mathrm{Na}^{+} / \mathrm{K}^{+}$pump activity (Vadász et al., 2008; Benziane et al., 2009; Gusarova et al., 2009). The $\mathrm{Na}^{+} / \mathrm{K}^{+}$ATPase is both energy requiring and essential for maintenance of the $\mathrm{K}^{+}$equilibrium, and we have already shown that disruption of the $\mathrm{Na}^{+} / \mathrm{K}^{+}$-ATPase using ouabain results in the generation of SD-like events in a concentration-dependent manner (Rodgers et al., 2009). An AMPK-induced shutdown of $\mathrm{Na}^{+} / \mathrm{K}^{+}$-ATPase activity when pumps are already subjected to ouabain could explain exacerbated SD-like events. Increased $\left[\mathrm{K}^{+}\right]_{\mathrm{o}}$ also explains the fast rhythm induced by $\mathrm{NaN}_{3}$ and AICAR. The subsequent slower rhythm could be caused by the effect of AMPK on ion channels. Carotid body glomus cells sense $\mathrm{O}_{2}$ availability to regulate breathing, and AMPK activation by $\mathrm{NaN}_{3}$ or hypoxia inhibits the background $\mathrm{K}^{+}$channels TREK- 1 and TREK-2 in these cells (Kréneisz et al., 2009). Similar modulation of $\mathrm{K}^{+}$channels in the locust could result in altered excitability and thus energy usage. Longer duration surges in preparations treated with AICAR could be caused by the decreased rate of $\left[\mathrm{K}^{+}\right]_{\mathrm{o}}$ decrease, indicating that $\left[\mathrm{K}^{+}\right]_{\mathrm{o}}$ clearance mechanisms were impaired during AMPK activation (Fig. 7a).

AMPK is expressed in cortical and hippocampal tissue and is involved in neuronal plasticity (Potter et al., 2010) and neuroprotection following stroke (McCullough et al., 2005). AMPK activation using the glycolytic inhibitor 2-deoxy-D-glucose, the mitochondrial toxin and anti-diabetes drug metformin, or AICAR prevented long- 
term potentiation (LTP) maintenance by suppressing the mammalian target of rapamycin (mTOR) pathway in the mouse hippocampus (Potter et al., 2010). It is likely that AMPK activation inhibited the mTOR signaling pathway and induction of LTP because these processes are energy intensive (Potter et al., 2010). AMPK inhibition or lack of activation results in heightened mTOR activity and inappropriate LTP induction that underlie conditions such as epilepsy that involve SD. Neuronal AMPK is elevated and activated after induction of cerebral ischemia in mice (McCullough et al., 2005). The volume of stroke damage is reduced by pharmacological inhibition of AMPK by either C75 (increases ATP levels) or compound-C and exacerbated by AICAR activation of AMPK (McCullough et al., 2005). Thus, AMPK activation following cerebral ischemia is detrimental to neuronal survival, whereas inactivation of AMPK may be neuroprotective (McCullough et al., 2005). We found that inhibition of AMPK using compound-C suppressed SD in $70 \%$ of preparations. In the few preparations where $\left[\mathrm{K}^{+}\right]_{\mathrm{o}}$ events did occur, there was no interruption of $\mathrm{VCPG}$ operation despite $\sim 60$ $\mathrm{mM}\left[\mathrm{K}^{+}\right]_{\mathrm{o}}$ increases measured at the recording site close to the vCPG. A novel finding in the current study was that inhibition of AMPK following initiation of ouabain-induced SD suppressed subsequent $\mathrm{SD}$-like events, where $\left[\mathrm{K}^{+}\right]_{\mathrm{o}}$ waves had a shorter duration and smaller amplitude. One possibility is that inhibition of AMPK using compound-C affected $\left[\mathrm{K}^{+}\right]_{\mathrm{o}}$ propagation throughout the MTG. Reduced $\left[\mathrm{K}^{+}\right]_{\mathrm{o}}$ diffusion across tissue would explain continued electrical activity and muted $\left[\mathrm{K}^{+}\right]_{\mathrm{o}}$ surges within the MTG. Recently, it has been suggested (Rodgers et al., 2010) that ouabaininduced repetitive SD in the locust resembles peri-infarct depolarizations that prevent the restoration of energy and increase the size of the cortical infarct (Fabricius et al., 2006; Dohmen et al., 2008; Dreier et al., 2009). Given the similarity between locust and mammalian SD phenomena, the modulatory effects of AMPK in our study are highly relevant for understanding the pathology of stroke and seizures.

We have shown that the locust vCPG responds to acute energy stress by switching motor pattern behavior and that manipulation of AMPK "tunes" the propensity of neuronal tissue to display SD-like events. The switch in rhythm frequency in response to $\mathrm{NaN}_{3}$ induced shutdown was mimicked by AMPK activation and reversed by AMPK inhibition. In addition, AMPK activation exacerbated ouabain-induced SD. We provide evidence that AMPK has a role in stress-induced comas and SD-like events in the locust and that it modulates the activity of a critical pattern-generating circuit.

\section{References}

Armstrong GAB, Rodgers CI, Money TGA, Robertson RM (2009) Suppression of spreading depression-like events in locusts by inhibition of the NO/cGMP/PKG pathway. J Neurosci 29:8225-8235.

Bartholomew GA, Barnhart MC (1984) Tracheal gases, respiratory gasexchange, body temperature and flight in some tropical cicadas. J Exp Biol 111:131-144.

Benziane B, Björnholm M, Lantier L, Viollet B, Zierath JR, Chibalin AV (2009) AMP-activated protein kinase activator A-769662 is an inhibitor of the $\mathrm{Na}^{+}-\mathrm{K}^{+}$-ATPase. Am J Physiol Cell Physiol 297:C1554-C1566.

Dohmen C, Sakowitz OW, Fabricius M, Bosche B, Reithmeier T, Ernestus RI, Brinker G, Dreier JP, Woitzik J, Strong AJ, Graf R (2008) Spreading depolarizations occur in human ischemic stroke with high incidence. Ann Neurol 63:720-728.

Dreier JP, Major S, Manning A, Woitzik J, Drenckhahn C, Steinbrink J, Tolias C, Oliveira-Ferreira AI, Fabricius M, Hartings JA, Vajkoczy P, Lauritzen M, Dirnagl U, Bohner G, Strong AJ (2009) Cortical spreading ischaemia is a novel process involved in ischaemic damage in patients with aneurysmal subarachnoid haemorrhage. Brain 132:1866-1881.

Evans AM (2006) AMP-activated protein kinase and the regulation of $\mathrm{Ca}^{2+}$ signalling in $\mathrm{O}_{2}$ sensing cells. J Physiol 574:113-123.

Fabricius M, Fuhr S, Bhatia R, Boutelle M, Hashemi P, Strong AJ, Lauritzen M
(2006) Cortical spreading depression and peri-infarct depolarization in acutely injured human cerebral cortex. Brain 129:778-790.

Fediuc S, Gaidhu MP, Ceddia RB (2006) Regulation of AMP-activated protein kinase and acetyl-CoA carboxylase phosphorylation by palmitate in skeletal muscle cells. J Lipid Res 47:412-420.

Guan F, Yu B, Qi GX, Hu J, Zeng DY, Luo J (2008) Chemical hypoxiainduced glucose transporter-4 translocation in neonatal rat cardiomyocytes. Arch Med Res 39:52-60.

Gusarova GA, Dada LA, Kelly AM, Brodie C, Witters LA, Chandel NS, Sznajder JI (2009) Alpha1-AMP-activated protein kinase regulates hypoxiainduced $\mathrm{Na}, \mathrm{K}-\mathrm{ATPase}$ endocytosis via direct phosphorylation of protein kinase C zeta. Mol Cell Biol 29:3455-3464.

Hardie DG, Hawley SA (2001) AMP-activated protein kinase: the energy charge hypothesis revisited. BioEssays 23:1112-1119.

Hardie DG, Scott JW, Pan DA, Hudson ER (2003) Management of cellular energy by the AMP-activated protein kinase system. FEBS Lett 546:113-120.

Hardie DG, Hawley SA, Scott JW (2006) AMP-activated protein kinase development of the energy sensor concept. J Physiol 574:7-15.

Jing M, Ismail-Beigi F (2007) Critical role of 5'-AMP-activated protein kinase in the stimulation of glucose transport in response to inhibition of oxidative phosphorylation. Am J Physiol Cell Physiol 292:C477-C487.

Kodiha M, Rassi JG, Brown CM, Stochaj U (2007) Localization of AMP kinase is regulated by stress, cell density, and signaling through the MEK $\rightarrow$ ERK1/2 pathway. Am J Physiol Cell Physiol 293:C1427-C1436.

Kréneisz O, Benoit JP, Bayliss DA, Mulkey DK (2009) AMP-activated protein kinase inhibits TREK channels. J Physiol 587:5819-5830.

Lease HM, Wolf BO, Harrison JF (2006) Intraspecific variation in tracheal volume in the American locust, Schistocerca americana, measured by a new inert gas method. J Exp Biol 209:3476-3483.

Li J, McCullough LD (2010) Effects of AMP-activated protein kinase in cerebral ischemia. J Cereb Blood Flow Metab 30:480-492.

Lindsley JE, Rutter J (2004) Nutrient sensing and metabolic decisions. Comp Biochem Physiol B 139:543-559.

Love S (2003) Apoptosis and brain ischaemia. Prog Neuropsychopharmacol Biol Psychiatry 27:267-282.

McCullough LD, Zeng Z, Li H, Landree LE, McFadden J, Ronnett GV (2005) Pharmacological inhibition of AMP-activated protein kinase provides neuroprotection in stroke. J Biol Chem 280:20493-20502.

Pan DA, Hardie DG (2002) A homologue of AMP-activated protein kinase in Drosophila melanogaster is sensitive to AMP and is activated by ATP depletion. Biochem J 367:179-186.

Potter WB, O’Riordan KJ, Barnett D, Osting SMK, Wagoner M, Burger C, Roopra A (2010) Metabolic regulation of neuronal plasticity by the energy sensor AMPK. PLoS One 5:e8996.

Robertson RM, Björnfors ER, Sillar KT (2010) Long-lasting effects of chemical hypoxia on spinal cord function in tadpoles. Neuroreport 21:943-947.

Rodgers CI, Armstrong GAB, Shoemaker KL, LaBrie JD, Moyes CD, Robertson RM (2007) Stress preconditioning of spreading depression in the locust CNS. PLoS ONE 2:e1366.

Rodgers CI, LaBrie JD, Robertson RM (2009) $\mathrm{K}^{+}$homeostasis and central pattern generation in the metathoracic ganglion of the locust. J Insect Physiol 55:599-607.

Rodgers CI, Armstrong GAB, Robertson RM (2010) Coma in response to environmental stress in the locust: A model for cortical spreading depression. J Insect Physiol 56:980-990.

Snider BJ, Gottron FJ, Choi DW (1999) Apoptosis and necrosis in cerebrovascular disease. Ann NY Acad Sci 893:243-253.

Spasić MR, Callaerts P, Norga KK (2009) AMP-activated protein kinase (AMPK) molecular crossroad for metabolic control and survival of neurons. Neuroscientist 15:309-316.

Staples JF, Buck LT (2009) Matching cellular metabolic supply and demand in energy stressed animals. Comp Biochem Physiol A Mol Integr Physiol 153:95-105.

Vadász I, Dada LA, Briva A, Trejo HE, Welch LC, Chen J, Tóth PT, Lecuona E, Witters LA, Schumacker PT, Chandel NS, Seeger W, Sznajder JI (2008) AMP-activated protein kinase regulates $\mathrm{CO}_{2}$-induced alveolar epithelial dysfunction in rats and human cells by promoting $\mathrm{Na}, \mathrm{K}-\mathrm{ATP}$ ase endocytosis. J Clin Invest 118:752-762.

Zhou G, Myers R, Li Y, Chen Y, Shen X, Fenyk-Melody J, Wu M, Ventre J, Doebber T, Fujii N, Musi N, Hirshman MF, Goodyear LJ, Moller DE (2001) Role of AMP-activated protein kinase in mechanism of metformin action. J Clin Invest 108:1167-1174. 